\title{
Economic Imperative versus Efforts for Preserving an Astronomical Site
}

\author{
Hakim L. Malasan ${ }^{1}$, Moch. Arief Senja, Bambang Hidayat and Moedji \\ Raharto \\ Bosscha Observatory at Lembang and Dept. Astronomy, ITB, \\ Bandung-Indonesia
}

\begin{abstract}
In this paper we report the gradual change of the physical environment of the Bosscha Observatory in Lembang, Indonesia. From photometric observations carried out in 1982 through 1993 we found a slight increase of the aerosol content in the atmosphere. However, light pollution from the expanding city of Bandung (pop. $2 \times 10^{6} ; 10 \mathrm{~km}$ away at $600 \mathrm{~m}$ altitude below the Observatory) has produced significant light scattering at zenith distances greater than $55^{\circ}$ toward the south.
\end{abstract}

\section{Introduction}

The Bosscha Observatory at Lembang, Java, Indonesia has enjoyed a relatively quiet and stable environment from its founding in the 1920 s until about 1980 . Its environmental change in the 1980s came about as a result of relatively fast economic development in the 1970s. This stimulated demands for land, housing and accordingly lights, primarily due to the increasing numbers of a new emerging middle class society. Their view of land and housing as economic assets seemed to be more prevalent than the real need for accommodation. Efforts to protect important scientific and cultural sites have been undertaken by the central and by local governments (Govt. Act. No. 5, 1992). Government Regulation No. 10 (1993) contains the outlines for protection of scientific and cultural institutions. In these decrees and regulations, views of environmental-friendly, sustainable development have been incorporated.

However, perceptions pertaining to this aspect, coupled with weak control from the executive agencies, have in many cases created problems. Physical development driven by economic imperative dominated the attitudes of many decision makers in the 1980s in such a way that the protective spirit of the law was occasionally put aside. Nevertheless, there was a concerted effort to protect the Observatory in the early 1970s when Parliament and the central government took the stern decision to forbid the development of a hotel near the Observatory.

Because of the inherent topographical nature of the Observatory grounds, lying on the top of a rather steep hill that serves as a water-catchment area, the local government has established a development-free zone within a radius of $2 \mathrm{~km}$ around the Observatory. This regulation has unfortunately not been

${ }^{1}$ Momentarily at the Gunma Observatory, Japan 
strictly observed due to increasing demands and unrealistic assessment about land use, as well as a narrow view with regard to physical constraints required by an astronomical observatory. The environmental engineers and scientists of the Institute of Technology of Bandung, as well as other environment-conscious groups, have made the case public by defending the views that preservation of lands immediately around the Observatory will not only do good for science, but it will also serve as a water reservoir for the people of the city of Bandung (population of 2 million, at an airline-distance of $10 \mathrm{~km}, 600 \mathrm{~m}$ below to the Observatory site). The view can be comprehended because of the nature of hills which surround the observatory complex.

Unfortunately, narrow interpretations of personal and human rights have occasionally brought conflict. The State Law No. 5 (1992) states that cultural and scientific sites, subject to a strict realistic definition, have to be protected. Protected areas around a scientific establishment include the supporting areas adjacent to it which make the institution function well. But here we are witnessing the confrontation of law versus economic imperative such as the increasing value of land and the pressure arising from population increase.

Stimulated by the volcanic eruption of Mt. Galunggung in $1982(100 \mathrm{~km}$ away from the Observatory), which spread fine dust particles for several weeks, and by the increasing stray light, we decided to monitor atmospheric transparency.

\section{Efforts and Observations}

It was not an easy task to convince the population that what they need is appropriate lighting directed groundward. We have therefore since the $1970 \mathrm{~s}$ carried out efforts to preserve the optical window for our work by persuading the local community to reduce outdoor light consumption. Public cooperation has resulted in keeping the light level at the zenith relatively constant over the last 20 years, at about $20^{\mathrm{m}} / \square^{\prime \prime}$ in the blue spectral region. Unfortunately, the advent of highways requiring brighter lighting has forced road engineers to introduce mercury lights. In addition, neon lights for advertisement and billboards have become more pronounced in the township of Lembang, $1 \mathrm{~km}$ away at an elevation of about $60 \mathrm{~m}$ below the Observatory. At the same time the previous use of incandescent lightbulbs has, unfortunately, been replaced by use of gas pressure lamps.

The expanding city of Bandung has produced more light output. Although it is partially screened by hills of altitudes higher than $700 \mathrm{~m}$, we lost our view towards the southern and eastern horizons at elevation angles below $30^{\circ}$ and $40^{\circ}$ respectively. Observation below this level produces noisy results due to the increasing stray light.

The topography around the Observatory has formed a natural barrier which has made it impossible for expansion of residential areas toward the Observatory. Accordingly, West Java Province Law forbade housing development projects on any hills of slope more than $40^{\circ}$ and, to ensure a development-free zone, areas within a radius of $2.5 \mathrm{~km}$ from the Observatory. The choice of the radius was again dictated by the topography of the region. The progress of technology, however, might change this as housing engineers claim that they technically 
can overcome the problem of building on steep slopes. But the conservationists maintain that preserving the hills creates an important natural asset for successful protection of water resources.

Disturbance by natural phenomena, such as volcanic eruptions, has occasionally disrupted the cleanliness of the atmosphere and changed seeing conditions considerably. The change of the atmospheric coefficient of extinction due to a nearby Galunggung volcano eruption has been reported by Hidayat and Malasan in 1985 and by Malasan et. al. (1984). The fine dust that prevailed in the atmosphere for weeks disrupted the atmosphere so much that observation of any kind was impossible. Assessment of the sky brightness has been given by Raharto (1995) and by Malasan and Raharto (1993), in which they described the observations of atmospheric coefficients of extinction from 1982 to 1993. Some changes were found and attributed to atmospheric pollution, in particular that caused by the increase of aerosol content in the atmosphere. There is also an indication that some change may be seasonal.

A thorough study of the sky brightness has been carried out by Senja (1999). The study, initiated by Malasan, was based on systematic photometric observations in 1994 on stars in IC 4665 . The results indicate that in the $U$-band the sky brightness at the zenith is $18^{\mathrm{m}} / \square^{\prime \prime}$. The value deteriorates rather fast, reaching $14^{\mathrm{m}} / \square^{\prime \prime}$ at $z=55^{\circ}$ to the south. The increase of incandescent lights in the cities may have been the cause of the sky glow, in particular toward the south and east. The increase of the blue absorption coefficient from 0.5 in 1982 to 0.7 in 1993 has been attributed to the increase of aerosol content, if we apply the Hayes and Latham (1975) and Guitierez-Moneno et. al. (1982) procedures to our data. The value in the $U$-band has been observed to increase from 0.6 in 1989 to about 0.9 in 1993.

The seeing at Lembang is generally good. Within 30 minutes after sunset star images become steady with an average annual seeing of $\sim 1^{\prime \prime}$. Continous observations of close visual double stars have not shown any appreciable change, except for short occasions when the seeing becomes more than $1^{\prime \prime} .5-2^{\prime \prime} .0$, the cause of which remains unknown. We plan to continue monitoring it.

\section{Conclusion}

Governmental good intentions have sometimes been opposed by ignorance and narrow interpretations of personal and human rights. In the last two years, due to economic decline, the formerly protected landscape immediately around the Observatory has been opened for non-agricultural purposes. This might cause serious problems in the future. Up until now the telescopes at Bosscha Observatory can be employed to observe objects down from the zenith to about $z \sim 55^{\circ}$ without serious problem. Beyond that point, observations at shorter wavelength regions will be troublesome. The double $24^{\prime \prime}-(61-\mathrm{cm})$ refractor $(f / 17)$ has fortunately not suffered too much.

To make the public aware of the beauty of astronomy and its needs, we continue to organize public meetings in order to disperse popular sciences. This effort is intended to implant a cultural identity that doing science is a noble endeavour. Scientifically, we are continuing to monitor the quality of the atmosphere and to increase our cooperative work through the Internet. 
Acknowledgments. One of us (B.H.) would like to express his gratitude to the Dean, Faculty of Mathematics and Science, ITB, for the contribution toward his expenses to attend this meeting. The financial support and understanding from the Leids Kerkhoven-Bosscha Foundation in the Netherlands for accommodation and travel is also gratefully acknowledged, without which he could not have attended the meeting.

\section{References}

Guiterez-Moneno, A., Moreno, H. \& Cortes, G. 1982, PASP, 94, 722

Hayes, A. S. \& Latham, D. W. 1975, ApJ, 197, 593, 722.

Hidayat, B. \& Malasan, H. L. 1985, Trans. IAU., vol. XIX B, p. 335

Malasan, H. L., Nurwendaya, C. \& Hidayat, B. 1984, Proceedings, Institut Teknologi Bandung., 17, 11 (in Indonesian)

Malasan, H. L. \& Raharto, M. 1997, Proceedings of the UN Meeting on Atmospheric Science, Held in Jakarta, Indonesia

Raharto, M. 1995, in Star Watching, National Astronomical Observatory, Tokyo, Japan, p. 61

Senja, M. A. 1999, Thesis, Dept. of Astronomy (in Indonesian) 